\title{
Author Correction: Smoking induces DNA methylation changes in Multiple Sclerosis patients with exposure-response relationship
}

\author{
Francesco Marabita ${ }^{1}{ }^{1}$, Malin Almgren ${ }^{1}$, Louise K. Sjöholm ${ }^{1}$, Lara Kular ${ }^{1}$, Yun Liu ${ }^{2,3}$, \\ Tojo James ${ }^{1}$, Nimrod B. Kiss ${ }^{1}$, Andrew P. Feinberg ${ }^{4}$, Tomas Olsson ${ }^{1}$, Ingrid Kockum ${ }^{1}$, \\ Lars Alfredsson $^{5}$, Tomas J. Ekström ${ }^{1} \&$ Maja Jagodic ${ }^{1}$
}

Correction to: Scientific Reports https://doi.org/10.1038/s41598-017-14788-w, published online 06 November 2017

This Article contains errors in the Methods section, under subsection 'Availability of data'.

"DNA methylation data are available on GEO under the accession numbers GSE60655 for the S cohort. The data from the B and PBMC cohorts are not publicly available at the submission date due to non-disclosure agreements for independent manuscripts, but are available from the corresponding author on reasonable request."

should read:

"DNA methylation data are available on GEO under the accession numbers GSE43976 for the S cohort. The data from the $\mathrm{B}$ and $\mathrm{PBMC}$ cohorts are not publicly available at the submission date due to non-disclosure agreements for independent manuscripts, but are available from the corresponding author on reasonable request."

(i) Open Access This article is licensed under a Creative Commons Attribution 4.0 International License, which permits use, sharing, adaptation, distribution and reproduction in any medium or format, as long as you give appropriate credit to the original author(s) and the source, provide a link to the Creative Commons license, and indicate if changes were made. The images or other third party material in this article are included in the article's Creative Commons license, unless indicated otherwise in a credit line to the material. If material is not included in the article's Creative Commons license and your intended use is not permitted by statutory regulation or exceeds the permitted use, you will need to obtain permission directly from the copyright holder. To view a copy of this license, visit http://creativecommons.org/licenses/by/4.0/.

(C) The Author(s) 2018

\footnotetext{
${ }^{1}$ Department of Clinical Neuroscience, Center for Molecular Medicine, Karolinska Institutet, Karolinska University Hospital, Stockholm, Sweden. '2Department of Biochemistry and Molecular Biology, The Ministry of Education Key Laboratory of Metabolism and Molecular Medicine, School of Basic Medical Sciences, Fudan University, Shanghai, China. ${ }^{3}$ State Key Laboratory of Medical Neurobiology, Fudan University, Shanghai, China. ${ }^{4}$ Center for Epigenetics and Departments of Medicine, Biomedical Engineering, and Mental Health, Johns Hopkins University, Baltimore,

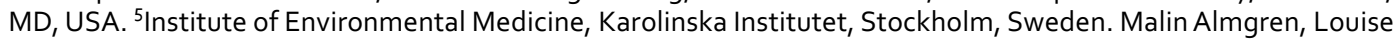
K. Sjöholm and Lara Kular contributed equally to this work.Tomas J. Ekström and Maja Jagodic jointly supervised this work. Correspondence and requests for materials should be addressed to M.J. (email: maja.jagodic@ki.se)
} 